\title{
28 Research Square \\ Fabrication and Mechanical Properties of Boron Nitride Nanotube Reinforced Boron Carbide Ceramics
}

\section{Bingsai Liu}

Guilin University of Technology

\section{Yuanping Gu}

Guilin Medical University Affiliated Hospital

\section{Yuchun Ji}

Guilin University of Technology

\section{Guoyuan Zheng}

Guilin University of Technology

\section{Feiwen Ma}

Guilin University of Technology

Jilin Wang ( $\nabla_{\text {jilinwang@glut.edu.cn ) }}$

Guilin University of Technology

Yi Wu

Guilin University of Technology

Fei Long

Guilin University of Technology

Bing Zhou

Guilin University of Technology

\section{Research Article}

Keywords: Boron carbide, Boron nitride nanotubes, Spark plasma sintering, Mechanical property

Posted Date: August 31st, 2020

DOI: https://doi.org/10.21203/rs.3.rs-67675/v1

License: (c) (i) This work is licensed under a Creative Commons Attribution 4.0 International License. Read Full License

Version of Record: A version of this preprint was published at Journal of the Ceramic Society of Japan on March 1st, 2021. See the published version at https://doi.org/10.2109/jcersj2.20211. 


\section{Abstract}

A series of $\mathrm{BNNTs} / \mathrm{B}_{4} \mathrm{C}$ composite ceramic were prepared by the spark plasma sintering (SPS) technology using boron carbide $\left(\mathrm{B}_{4} \mathrm{C}\right)$ powders as the matrix and boron nitride nanotubes (BNNTs) as the toughening phase. The XRD, SEM, TEM and HR-TEM were used to characterize the $\mathrm{B}_{4} \mathrm{C}$ samples. The influence of sintering temperature, BNNTs content and matrix particle size on the microstructures and mechanical properties of $\mathrm{B}_{4} \mathrm{C}$ composite ceramics, as well the toughening mechanism were investigated in detail. The experimental results showed that changing the particle size of the powder, increasing the sintering temperature and adding BNNTs could significantly improve the mechanical properties of the material. The ceramic samples obtained by adding $5 \mathrm{wt} . \%$ BNNTs content sintered at $1750^{\circ} \mathrm{C}$ displayed the best mechanical properties. Its relative density, microhardness and fracture toughness respectively were $99.41 \%, 32.68 \mathrm{GPa}$ and $6.87 \mathrm{Mpa} \cdot \mathrm{m}^{1 / 2}$, respectively. In particular, the fracture toughness value of the BNNTs $/ B_{4}$ C composite ceramic was $54.59 \%$ higher than that of $B_{4} C$ ceramics without BNNTs.

\section{Introduction}

Boron carbide $\left(\mathrm{B}_{12} \mathrm{C}_{3}\right.$ or $\left.\mathrm{B}_{4} \mathrm{C}\right)$ is a kind of oxide light solid material, its single hexahedron diamond crystal cell contains 15 atoms (composition $\mathrm{B}_{11} \mathrm{C}$ icosahedron and a linear C-B-C three atomic chain, both by covalent bond connection, form a stable structure) $[1,2]$. The highly stable covalent bond between $B$ and $\mathrm{C}$ atoms in $\mathrm{B}_{4} \mathrm{C}$ and its special crystal structure make $\mathrm{B}_{4} \mathrm{C}$ have many excellent physical and chemical properties. For example, low density $\left(2.52 \mathrm{~g} \cdot \mathrm{cm}^{-3}\right.$ ), high hardness (> $30 \mathrm{Gpa}$, second only to diamond and cubic boron nitride), high melting point $\left(2450^{\circ} \mathrm{C}\right)$, high temperature wear resistance $\left(1400^{\circ} \mathrm{C}\right.$ to 0.05$)$, low thermal expansion coefficient (about $5.73 \times 10^{-6} /{ }^{\circ} \mathrm{C}$ ) and the thermoelectric performance, thermal neutron absorption ability, etc [3-6]. These properties make $B_{4} C$ have broad application prospects in high-performance engineering ceramics, cutting tools, composite armor, body armor and other national defense and military industries. It is an important strategic material material in today's national economy and national defense construction $[7,8]$. However, the high covalent bonds of $B_{4} C$ content $(>90 \%)$ and high melting point, resulting in $\mathrm{B}_{4} \mathrm{C}$ ceramic sintering difficulties and poor toughness(2-4 $\mathrm{Mpa} \cdot \mathrm{m}^{1 / 2}$ ), these make the mechanical properties unable to be further improved, and greatly limits the application range of $\mathrm{B}_{4} \mathrm{C}$ ceramics as structural ceramics [9].

At present, particle toughening and whisker (fiber) toughening are effective methods to improve fracture toughness of ceramics. Baris Yavas et al used SPS technology to prepare CNTs/ ${ }_{4} \mathrm{C}$ ceramic composites with carbon nanotubes (CNTs) as toughening phase [10]. The results showed that adding CNTs or increasing the heating rate can improve the fracture toughness of $\mathrm{B}_{4} \mathrm{C}$ ceramics. Recent years studies have found that BNNTs have better comprehensive mechanical properties, chemical stability and oxidation resistance than CNTs, making them an ideal toughening material [11, 12]. In 2018, Li used hotpressing sintering technology to study silicon nitride $\left(\mathrm{Si}_{3} \mathrm{~N}_{4}\right)$ ceramics added with and without boron nitride nanotubes (BNNTs) were fabricated. The results showed that BNNTs can enhance the fracture 
toughness of $\mathrm{Si}_{3} \mathrm{~N}_{4}$ dramatically, which increases from $7.2 \mathrm{Mpa} \cdot \mathrm{m}^{1 / 2}$ (no BNNTs) to $10.4 \mathrm{Mpa} \cdot \mathrm{m}^{1 / 2}(0.8$ wt.\% BNNTs) [13]. Zeng Xiaojun et al studied the microstructure and mechanical properties of BNNTs/ $B_{4} C$ composite ceramics by hot-pressing sintering process, and the results showed that the bending strength and fracture toughness of the composite with $1.5 \mathrm{wt} . \%$ BNNTs increased by $28 \%$ and $31.5 \%$, respectively $[14,15]$.

In this paper, the high-activity $\mathrm{B}_{4} \mathrm{C}$ micro-nano powders was used as the matrix and the BNNTs/ $\mathrm{B}_{4} \mathrm{C}$ composite ceramics were prepared by SPS low-temperature rapid sintering technology. The influence of the sintering temperature, BNNTs content and matrix particle size on the microstructures and mechanical properties of $\mathrm{B}_{4} \mathrm{C}$ composite ceramics, as well the toughening mechanism were also investigated in detail.

\section{Experimental section}

\subsection{Experimental Reagents}

The commercially available micron-sized $\mathrm{B}_{4} \mathrm{C}$ powders were purchased from Mudanjiang Boron Carbide Co., PR China (Particle size of about $3.5 \mu \mathrm{m}$, purity >98\%,Fig. 1(a)), homemade $\mathrm{B}_{4} \mathrm{C}$ nano-powders (Fig. 1(b)) [16], homemade BNNTs (Figs. 1(a) and (b)) [17, 18].

\subsection{Preparation of $\mathrm{BNNTs} / \mathrm{B}_{4} \mathrm{C}$ composite ceramics}

Raw materials and pre-heat treatment: using homemade $\mathrm{B}_{4} \mathrm{C}\left(\mathrm{H}-\mathrm{B}_{4} \mathrm{C}\right)$ nano-powders and commercial $\mathrm{B}_{4} \mathrm{C}$ $\left(\mathrm{C}-\mathrm{B}_{4} \mathrm{C}\right.$ ) micro-powders (Figs. $1(\mathrm{a})$ and $7(\mathrm{~b})$ ) as the experimental matrix materials. First, mixing $\mathrm{B}_{4} \mathrm{C}$ BNNTs according to a certain ratio; Then, putting the mixture into the mixing tank and grind for $6 \mathrm{~h}$; Finally, the obtained mixture was subjected to pickling (removal of impurities) water washing, ethanol washing, suction filtration and vacuum drying and storage.

SPS sintering of the mixture: taking the mixture out of the vacuum drying oven, weighing an appropriate amount of the mixture and grinding for $15 \mathrm{~min}$, putting the ground mixture into a graphite mold with a diameter of $15 \mathrm{~mm}$ for SPS sintering. The sintering temperature was $1700^{\circ} \mathrm{C}$, the heating rate was $200^{\circ} \mathrm{C} / \mathrm{min}$, the sintering pressure was $30 \mathrm{MPa}$, and the holding time was $5 \mathrm{~min}$. After the sintering, the graphite layer on the surface of the sintered sample was removed, then polished, ultrasonically cleaned and dried to perform related test and characterization. The experimental technical parameters of the samples are shown in Table 1 
Table 1

Experimental technical parameters of the sample

\begin{tabular}{|llllll|}
\hline Formulation & $\begin{array}{l}\mathrm{B}_{4} \mathrm{C} \\
\text { types }\end{array}$ & $\begin{array}{l}\mathrm{B}_{4} \mathrm{C} \text { content } \\
/ \text { wt.\% }\end{array}$ & $\begin{array}{l}\text { BNNTs content } \\
/ \text { wt.\% }\end{array}$ & $\begin{array}{l}\text { Sintering } \\
\text { temperature/ }{ }^{\circ} \mathrm{C}\end{array}$ & $\begin{array}{l}\text { Sintering } \\
\text { method }\end{array}$ \\
\hline $\mathrm{S} 1$ & $\mathrm{C}-\mathrm{B}_{4} \mathrm{C}$ & 100 & 0 & 1700 & $\mathrm{SPS}$ \\
\hline $\mathrm{S} 2$ & $\mathrm{C}-\mathrm{B}_{4} \mathrm{C}$ & 95 & 5 & 1700 & $\mathrm{SPS}$ \\
\hline $\mathrm{S} 3$ & $\mathrm{C}-\mathrm{B}_{4} \mathrm{C}$ & 90 & 10 & 1700 & $\mathrm{SPS}$ \\
\hline $\mathrm{S} 5$ & $\mathrm{H}-\mathrm{B}_{4} \mathrm{C}$ & 100 & 0 & 1700 & $\mathrm{SPS}$ \\
\hline $\mathrm{S} 6$ & $\mathrm{H}-\mathrm{B}_{4} \mathrm{C}$ & 95 & 5 & 1700 & $\mathrm{SPS}$ \\
\hline $\mathrm{S} 7$ & $\mathrm{H}-\mathrm{B}_{4} \mathrm{C}$ & 90 & 10 & 1700 & $\mathrm{SPS}$ \\
\hline $\mathrm{S} 8$ & $\mathrm{H}-\mathrm{B}_{4} \mathrm{C}$ & 95 & 5 & 1600 & $\mathrm{SPS}$ \\
\hline $\mathrm{S} 9$ & $\mathrm{H}-\mathrm{B}_{4} \mathrm{C}$ & 95 & 5 & 1750 & $\mathrm{SPS}$ \\
\hline
\end{tabular}

\subsection{Characterization}

The relative density of the sintered sample was measured by the Archimedes method. The microstructure of the cross-section of the ceramic bulk sample was characterized by scanning electron microscope (SEM, FEI Quanta FEG 250 and Hitachi S-3400), transmission electron microscopy (TEM, JEOL JEM2100F and Philip CM12). Vickers hardness tester and indentation method were used to test the microhardness and fracture toughness of the samples (the 430 Vickers Hardness Tester, Walbert, USA). The extrinsic load and dwell time of hardness test were respectively $5 \mathrm{~N}$ and $10 \mathrm{~s}$. The extrinsic load and dwell time of fracture toughness test were $15 \mathrm{~N}$ and $15 \mathrm{~s}$. And five positions on top and bottom surfaces were respectively tested to determine the average value of microhardness and fracture toughness test.

\section{Results And Discussion}

\subsection{The influence of BNNTs content}

Figure 2 is the XRD pattern of $\mathrm{B}_{4} \mathrm{C}$ samples fabricated by sintering at $1700^{\circ} \mathrm{C}$ with different adding amounts of BNNTs. It can be seen from the Fig. 2 that there were obvious XRD characteristic diffraction peaks of $\mathrm{B}_{4} \mathrm{C}$ and $\mathrm{h}-\mathrm{BN}$ in the samples of $\mathrm{S}-\mathrm{B}_{4} \mathrm{C}-5 \mathrm{wt}$.\% BNNT and $\mathrm{S}-\mathrm{B}_{4} \mathrm{C}-10 \mathrm{wt}$.\% BNNTs, and no other impurity peaks were found. This shown that the content of amorphous carbon in commercial boron carbide powder was relatively low. For samples Z-B ${ }_{4} \mathrm{C}-5 \mathrm{wt} . \%$ BNNTs and Z-B ${ }_{4} \mathrm{C}-10 \mathrm{wt}$.\% BNNTs, there were obvious graphitic carbon peaks in the corresponding XRD spectra. This showed that part of the 
amorphous carbon contained in the home-made boron carbide powder was completely transformed into crystalline carbon (graphite) under high temperature conditions.

The fracture morphology of ceramic samples with different ceramic matrix and different contents of BNNTs is shown in Fig. 3. It could be seen from Fig. 3 that all the sample sections showed low porosity and high density. It could be seen from Fig. 3(e) that there were some pores of about $0.5 \mu \mathrm{m}$ and a small amount of white impurity particles (shown in the white wire frame) on the cross-section of $\mathrm{C}-\mathrm{B}_{4} \mathrm{C}$ ceramic. It was also found that the section of the $\mathrm{C}-\mathrm{B}_{4} \mathrm{C}$ sample was flat, and it was speculated that the main fracture mode was transgranular fracture. When adding $5 \mathrm{wt}$ \% BNNTs, the $\mathrm{C}-\mathrm{B}_{4} \mathrm{C}-5 \mathrm{wt}$.\% BNNTs sample appeared some intergranular fractures (Fig. 3(g)), indicating that the addition of a certain amount of BNNTs changed the fracture mode of $\mathrm{B}_{4} \mathrm{C}$ ceramics. When the content of BNNTs was further increased to $10 \mathrm{wt} \%$, there were basically no pores in the cross section of C-B ${ }_{4} \mathrm{C}-10 \mathrm{wt} . \%$ BNNTs, which was basically close to the theoretical density. It was worth noting that the cross-sections of $\mathrm{H}-\mathrm{B}_{4} \mathrm{C}$ and $\mathrm{H}-\mathrm{B}_{4} \mathrm{C}-5 \mathrm{wt} . \%$ BNNTs ceramics showed some grooves formed after the $\mathrm{B}_{4} \mathrm{C}$ grains were pulled out during the fracture process of the sample (shown in the square wire frame in Figs. 3(a) and 3(b). When the content of BNNTs was too high, the agglomeration between nanotubes was significant (Figs. 3(d) and 3(h)). This kind of agglomeration was equivalent to micron-sized defects, and this loose agglomerate will also produce more void defects at the junction of the nanotube and the matrix, which will hinder the densification of the matrix $[14,19]$.

It can be seen from Fig. 4(a) that when the content of BNNTs was the same, the $\mathrm{B}_{4} \mathrm{C}$-based ceramic composite material with $\mathrm{H}-\mathrm{B}_{4} \mathrm{C}$ nano-powders as the matrix had a higher relative density than the $\mathrm{B}_{4} \mathrm{C}$ based ceramic composite material with $\mathrm{C}-\mathrm{B}_{4} \mathrm{C}$ powders as the matrix. The reason may be that the particles of $\mathrm{H}-\mathrm{B}_{4} \mathrm{C}$ nano-powders are much smaller than micron-sized $\mathrm{C}-\mathrm{B}_{4} \mathrm{C}$ powders particles, under the same conditions, the smaller the particle size of the raw material, the more conducive to obtaining highdensity ceramic samples. When $\mathrm{C}-\mathrm{B}_{4} \mathrm{C}$ was used as the matrix, the relative density of the $\mathrm{B}_{4} \mathrm{C}-\mathrm{BNNTS}$ ceramic composite material increased accordingly with the increase of BNNTs content. The reason is that because BNNTs have a relatively small particle size, in the ceramic sintering process, BNNTs are easy to fill the gaps between $\mathrm{B}_{4} \mathrm{C}$ micron grains. However, when $\mathrm{H}-\mathrm{B}_{4} \mathrm{C}$ was used as the matrix, the relative density of $\mathrm{B}_{4} \mathrm{C}-\mathrm{BNNTS}$ ceramic composite material decreased slightly with the increase of BNNTs content [20], and the relative density of the four was close to the theoretical density.

It can be seen from Figs. 4(b) that under the same conditions, $\mathrm{H}-\mathrm{B}_{4} \mathrm{C}$ as a matrix had a higher hardness than $\mathrm{C}-\mathrm{B}_{4} \mathrm{C}$. The reason may be that the particle size of $\mathrm{H}-\mathrm{B}_{4} \mathrm{C}$ powders are nanometer, while the particle size of $\mathrm{C}-\mathrm{B}_{4} \mathrm{C}$ powders are micrometer. Under the same conditions, the smaller the particle size of the raw material, the more conducive it is to obtain ceramic samples with high density and high hardness. When the matrix was the same, with the increase of BNNTs content, the hardness of the ceramic composite material gradually decreased. The reason may be as the content of BNNTs continued to increase, the possibility of nanotube agglomeration became higher, and the defects and matrix pores introduced by 
agglomerations will increase, which will reduced the continuity and density of the ceramic matrix, which will eventually lead to the hardness of the ceramic material decreases [21].

It can be seen from Fig. 4 (c) that whether the ceramic matrix is $\mathrm{C}-\mathrm{B}_{4} \mathrm{C}$ or $\mathrm{H}-\mathrm{B}_{4} \mathrm{C}$, as the content of BNNTs increased, the fracture toughness of the composite ceramics first increased and then decreased. When the content of BNNTs was $5 \mathrm{wt} . \%$, the fracture toughness of $\mathrm{C}-\mathrm{B}_{4} \mathrm{C}-5 \mathrm{wt} . \% \mathrm{BNNTs}$ and $\mathrm{H}-\mathrm{B}_{4} \mathrm{C}-5 \mathrm{wt} . \% \mathrm{BNNTs}$ ceramics were both the best, respectively $4.31 \mathrm{Mpa} \cdot \mathrm{m}^{1 / 2}$ and $5.92 \mathrm{Mpa} \cdot \mathrm{m}^{1 / 2}$. The results showed that adding an appropriate amount of BNNTs could effectively improve the fracture toughness of $\mathrm{B}_{4} \mathrm{C}$ ceramics. The reason is that BNNTs are uniformly distributed on the grain boundaries and grains of the $\mathrm{B}_{4} \mathrm{C}$ matrix. During the crack propagation process, the excellent mechanical properties of the nanotubes can effectively prevent the further propagation of the crack, thereby improving the fracture toughness of the ceramic [14,22-24]. However, with the further increase of the BNNTs content, the agglomeration of the nanotubes continued to increase, which caused the pores around the nanotubes to increase, which easily induced crack propagation and reduced the toughness of the composite material. Thus, the optimum BNNTs content for $\mathrm{B}_{4} \mathrm{C}$ composite ceramics in our study is determined to be $5 \mathrm{wt} . \%$. In addition, it was found that $\mathrm{H}-\mathrm{B}_{4} \mathrm{C}$ has better mechanical properties than $\mathrm{C}-\mathrm{B}_{4} \mathrm{C}$ under the same conditions.

\subsection{The influence of sintering temperature}

The mechanical properties of superhard structure ceramics are directly determined by its microstructure, which is affected by the sintering temperature. Figure 5 illustrates the SEM patterns of $\mathrm{H}-\mathrm{B}_{4} \mathrm{C}-5 \mathrm{wt} . \%$ BNNTs samples section at different temperatures. It can be seen from Fig. 5(a) that at low temperatures, there existed more pores and pits in sintered samples, and the powder particles failed to combine with each other to form obvious grain boundaries. With the increase of the sintering temperature, the sample grains tended to fuse, and the grain size increased gradually, the pores reduced and closed, and the density increased. When the sintering temperature reached $1750^{\circ} \mathrm{C}$, the sample was almost completely sintered. The mainly reason is as the sintering temperature increases, the process of surface diffusion and interface diffusion mass transfer speeds up, the density increases, and the pores are continuously eliminated. When the sintering temperature was $1800^{\circ} \mathrm{C}$, the sample section was uneven, which may be due to the high temperature, the grain boundary migration rate was greater than the pore migration rate, the grain size increased significantly, and small closed pores were formed inside the grains [15].

It can be seen from Fig. 6 that with the increase of the sintering temperature, the change trend of the microhardness of the $\mathrm{H}-\mathrm{B}_{4} \mathrm{C}-5 \mathrm{wt} \%$ BNNTs ceramic sample was the same as the change trend of the relative density of the $\mathrm{B}_{4} \mathrm{C}$ ceramic, indicating that the particle rearrangement of the $\mathrm{B}_{4} \mathrm{C}$ ceramic mixed with BNNTs was enhanced in the sintering process. With the increase of the sintering temperature, the driving force of $\mathrm{B}_{4} \mathrm{C}$ sintering continued to increase, and the continuous growth of crystal grains increased the sintering densification of ceramics, which made the microhardness increase, gradually. When the sintering temperature was $1750^{\circ} \mathrm{C}$, the microhardness and relative density of the sintered sample were the largest, which are $99.14 \%$ and $32.68 \mathrm{GPa}$, respectively. As the temperature continued to 
rise, the particle size grew rapidly, and more pore defects were produced, which caused a decrease in the density and hardness of the composite material.

It can be seen from Fig. 6(b) that the trend of the fracture toughness of the composite material with the sintering temperature was similar to that of the microhardness. When the temperature was lower than $1750^{\circ} \mathrm{C}$, the fracture toughness of the ceramic continued to increase as the temperature rose. When temperature reached $1750^{\circ} \mathrm{C}$, the fracture toughness was the largest at $6.87 \mathrm{Mpa} \cdot \mathrm{m}^{1 / 2}$. Thus, the optimum sintering temperature for $\mathrm{H}-\mathrm{B}_{4} \mathrm{C}-5 \mathrm{wt}$.\% ceramics in our study is determined to be $1750^{\circ} \mathrm{C}$.

The reason is that when the sintering temperature increases, the bonding strength of the heterogeneous interface between BNNTs and the $\mathrm{B}_{4} \mathrm{C}$ ceramic matrix increases. When the crack extends to the surface of the nanotube, the crack propagation path or crack growth energy is increased through crack deflection, bridging and pull-out effects. As the temperature continued to rise, the fracture toughness of ceramic materials decreased significantly. The reason is the $\mathrm{B}_{4} \mathrm{C}$ grains grow rapidly, and the toughening effect of BNNTs is difficult to offset the abnormal growth of $\mathrm{B}_{4} \mathrm{C}$ grains and the abnormal interface strength reduction, which leads to a significant reduction in the fracture toughness of the composite material [20].

\subsection{Toughening mechanism}

Figure 7 shows the microstructure of the BNNTs/ $\mathrm{B}_{4} \mathrm{C}$ composites. From Fig. $7(\mathrm{a})$, we can find that there is a relatively long groove (marked by the frame) formed between the crystal planes due to the pulling out of the nanotube. In addition, the nanotubes marked by the arrows in the Figure shown a clear hollow structure and the phenomenon of cracking occur, which was caused by the force during the cracking process. It could be inferred from this phenomenon that the mode of strengthening and toughening the $\mathrm{B}_{4} \mathrm{C}$ ceramic was the fiber pull-out effect. In Fig. 7(c), BNNTs was connected between the two grain boundaries. It was speculated that the mechanism of strengthening and toughening the ceramic was the fiber bridging mechanism.

\section{Conclusions}

$\mathrm{B}_{4} \mathrm{C}$ ceramics with and without BNNTs are fabricated by spark plasma sintering method. Regardless of whether the $\mathrm{B}_{4} \mathrm{C}$ ceramic matrix is micron-powders or nano-powders, adding of BNNTs enhances the fracture toughness greatly. The optimum BNNTs content is $5 \mathrm{wt} . \%$. Moreover, adding a certain amount of BNNTs has little effect on the microhardness and density of $\mathrm{B}_{4} \mathrm{C}$-based ceramics. The relative density, microhardness and fracture toughness of $\mathrm{H}-\mathrm{B}_{4} \mathrm{C}-5 \mathrm{wt}$.\% BNNTs ceramics increased with the increase of sintering temperature, reaching $99.41 \%, 32.68 \mathrm{GPa}$ and $6.87 \mathrm{Mpa} \cdot \mathrm{m}^{1 / 2}$ (maximum value) at $1750^{\circ} \mathrm{C}$. However, too much BNNTs can degrade the fracture toughness of the ceramics instead. The toughening mechanism may be pull-out of BNNTs, bridging of BNNTs and crack deflection. It is hoped that the research in this work can provide certain experimental and theoretical reference for the research on the strengthening and toughening of boron carbide-based ceramics. 


\section{Declarations}

\section{Acknowledgments}

The authors acknowledge the financial support from National Natural Science Foundation of China (No.51972071), Guangxi Natural Science Foundation (2018GXNSFAA050032), Non-Ferrous Metals and Materials Processing New Technology Ministry of Education Key Laboratory Open Fund Project (No. 19KF-5 and No.19AA-14), Guilin Scientific Research and Technology Development Program (No.20190204-2).

\section{References}

1. Lazzari R, Vast N, Besson J, et al. Atomic structure and vibrational properties of icosahedral $\mathrm{B}_{4} \mathrm{C}$ boron carbide. Phys Rev Lett 1999, 83: 3230-3233.

2. Mauri F, Vast N, Pickard $\mathrm{C} J$. Atomic structure of icosahedral $\mathrm{B}_{4} \mathrm{C}$ boron carbide from a first principles analysis of NMR spectra. Phys Rev Lett 2001, 87: 085506.

3. Mori T. Thermoelectric and magnetic properties of rare earth borides: Boron cluster and layered compounds. J Solid State Chem 2019, 275: 70-82.

4. Werheit H, Leithejasper A, Tanaka T, et al. Some properties of single-crystal boron carbide. J Solid State Chem 2004, 177: 575-579.

5. Watts JL, Spratt HJ, Talbot PC, et al. Precision structural and phase analysis of boron carbide. Ceramics International 2020, 46: 11033-11040.

6. Suri AK, Subramanian C, Sonber JK, Murthy TS. Synthesis and consolidation of boron carbide: a review. Int Mater Rev 2020, 55: 4-40.

7. Thevenot F. Boron carbide a comprehensive review. J Eur Ceram Soc 1990, 6: 205-225.

8. Domnich V, Reynaud S, Haber RA, et al. Boron carbide: Structure, properties, and stability under stress. J Am Ceram Soc 2011, 94: 3605-3628.

9. Xie KY, Toksoy MF, Kuwelkar K, et al. Effect of alumina on the structure and mechanical properties of spark plasma sintered boron carbide. J Am Ceram Soc 2014, 97: 3710-3718.

10. Yavas B, Sahin F, Yucel $O$, et al. Effect of particle size, heating rate and CNT addition on densification, microstructure and mechanical properties of $\mathrm{B}_{4} \mathrm{C}$ ceramics. Ceramics International 2015, 41: 89368944.

11. Chen $\mathrm{Y}, \mathrm{Bi} \mathrm{J}$, Wang $\mathrm{W}$, et al. Toughening in boron nitride nanotubes/silicon nitride composites. Mater Sci Eng A 2014, 590: 16-20.

12. Wang $\mathrm{W}, \mathrm{Bi} \mathrm{J}$, Sun $\mathrm{K}$, et al. Fabrication of alumina ceramic reinforced with boron nitride nanotubes with improved mechanical properties. J Am Ceram Soc 2011, 94: 3636-3640.

13. Li TF, Chen, YJ, Li, W, et al. Fabrication and mechanical properties of boron nitride nanotube reinforced silicon nitride ceramics. Ceramics International 2018, 44: 6456-6460. 
14. Zeng XJ, Liu WL, Feng ZQ, et al. Microstructure and mechanical properties of BNNTs/B $\mathrm{B}_{4} \mathrm{C}$ ceramic composites. J Ceram 2013, 34: 438-442.

15. Zeng XJ, Liu WL, Feng ZQ, et al. Effect of sintering temperature on microstructure and mechanical properties of BNNTs/B_4C ceramic composites. China Ceramics 2014, 41: 7021-7027.

16. Wang JL, Long F, Wang WM, et al. Reaction coupling preparation of high sintering activity boron carbide nano-powders. Ceramics International 2016, 42: 6969-6977.

17. Wang JL, Li Z, Gu YP, et al. Synthesis of boron nitride nanotubes using glass fabrics as catalyst growth framework. Ceramics International 2015, 41: 1891-1896.

18. Wang JL, Peng D, Long F, et al. Glass fabrics self-cracking catalytic growth of boron nitride nanotubes. Solid State Sci 2017, 64: 23-28.

19. Li X, Gao Y, Pan W, et al. Fabrication and characterization of $B_{4} C$-based ceramic composites with different mass fractions of hexagonal boron nitride. Ceramics International, 2015, 41: 27-36.

20. Jiang $T$, Jin Z, Yang J, et al. Investigation on the preparation and machinability of the $B_{4} C / B N$ nanocomposites by hot-pressing process. J Mater Process Technol 2009, 209: 561-571.

21. Alexander R, Murthy TSRC, Ravikanth KV, et al. Effect of graphene nano-platelet reinforcement on the mechanical properties of hot pressed boron carbide based composite. Ceramics International 2018, 44: 9830-9838.

22. Chen M, Yin Z, Yuan J, et al. Microstructure and properties of a graphene platelets toughened boron carbide composite ceramic by spark plasma sintering. Ceramics International 2018, 44: 1537015377.

23. Wang WL, Bi JQ, Wang SR, et al. Microstructure and mechanical properties of alumina ceramics reinforced by boron nitride nanotubes. J Eur Ceram Soc 2011, 31: 2277-2284.

24. Xu JJ, Bai YJ , Wang WL, et al. Toughening and reinforcing zirconia ceramics by introducing boron nitride nanotubes. Materials ence \& Engineering A 2012, 546: 301-306.

\section{Figures}





\section{Figure 1}

The typical SEM images of C-B4C (a), H-B4C (b) and BNNTs (c), (d). 


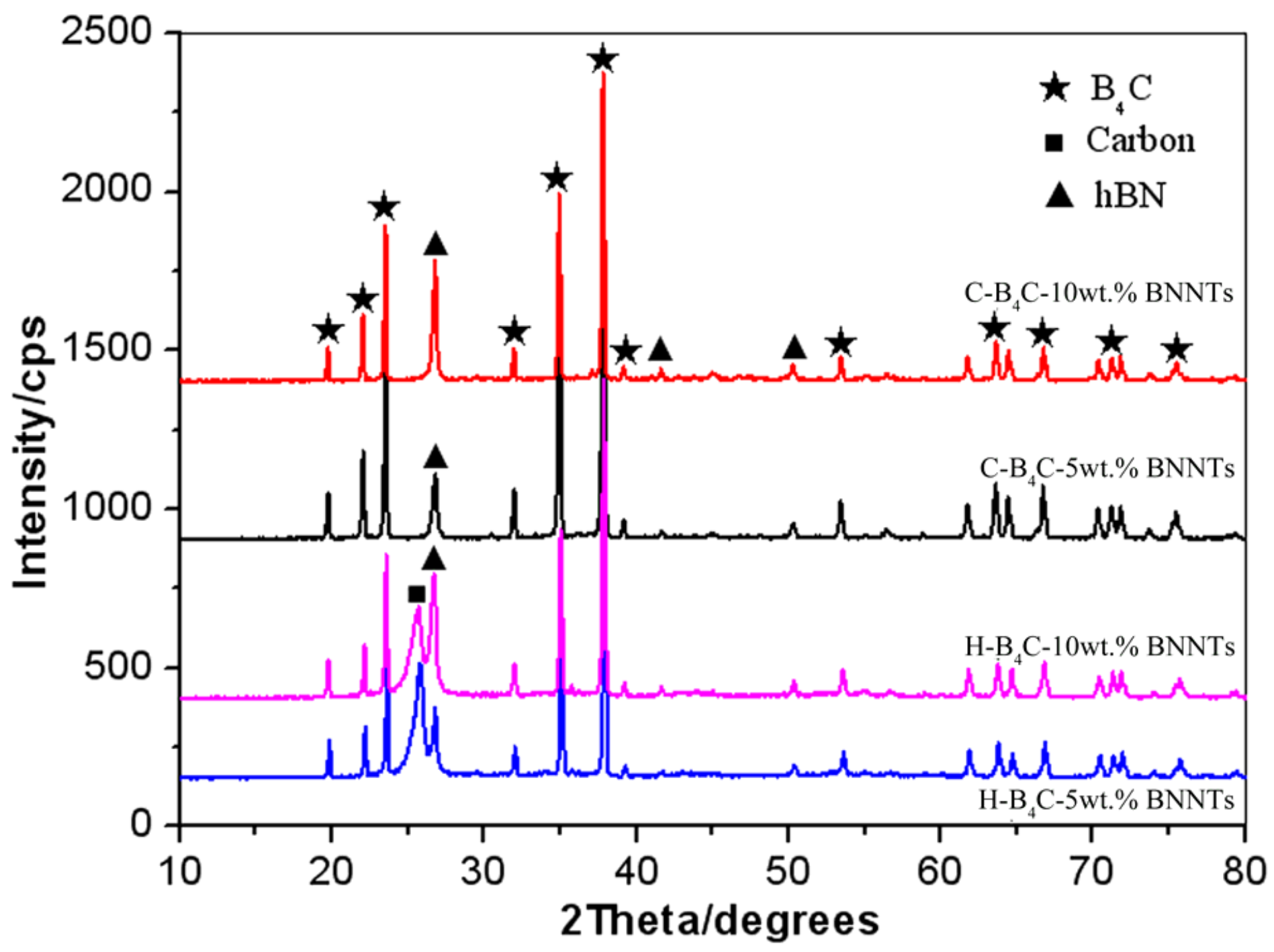

Figure 2

XRD patterns of $\mathrm{B} 4 \mathrm{C}$ samples fabricated by sintering at $1700^{\circ} \mathrm{C}$ with different adding amounts of BNNTs (wt.\%). 

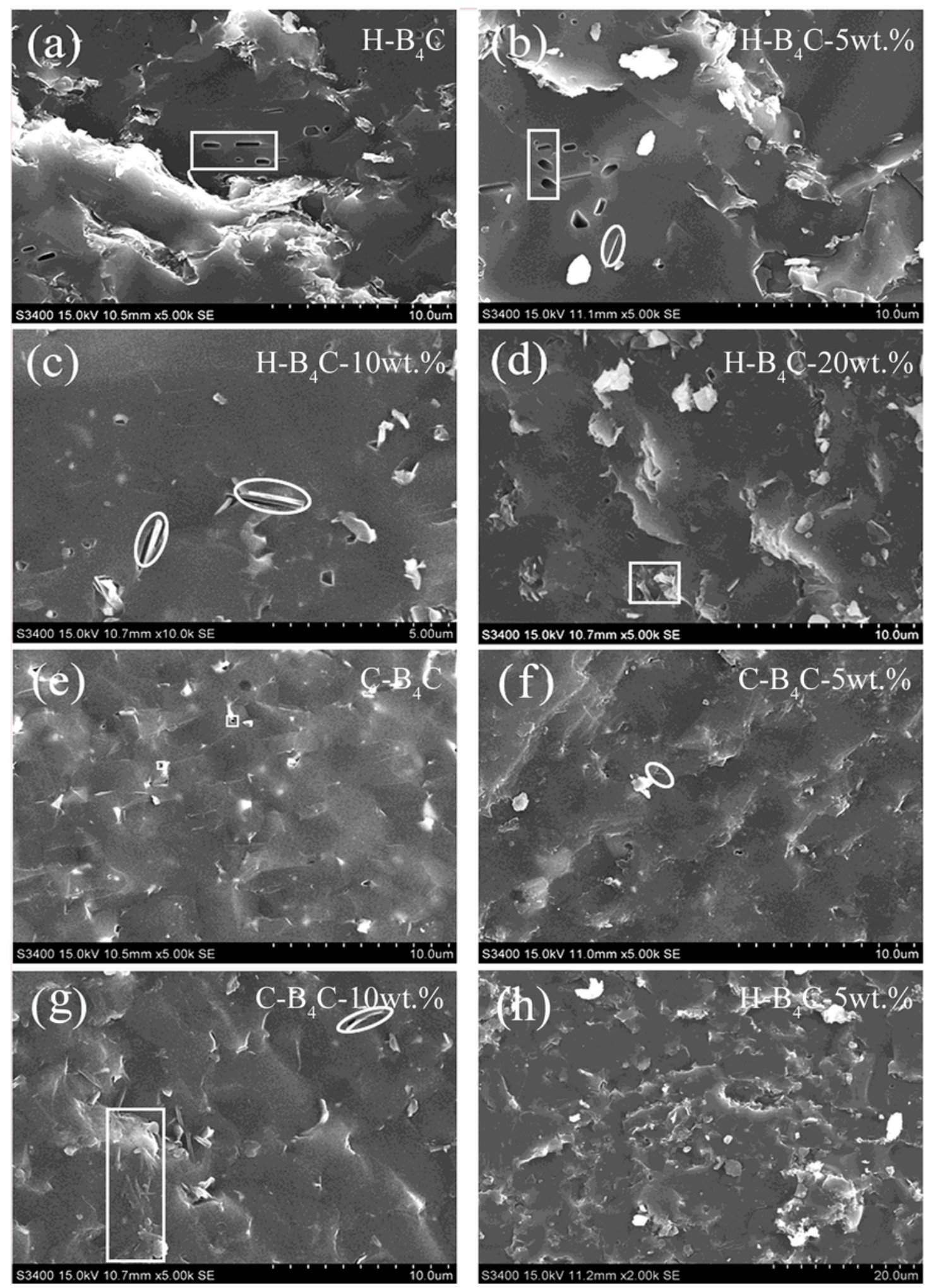

Figure 3

SEM images of the fracture surfaces of B4C samples fabricated with different adding amounts of BNNTs. 



Figure 4

The relative densities, microhardness and fracture toughness of B4C samples prepared by sintering at $1700^{\circ} \mathrm{C}$ with different adding amounts of BNNTs. 


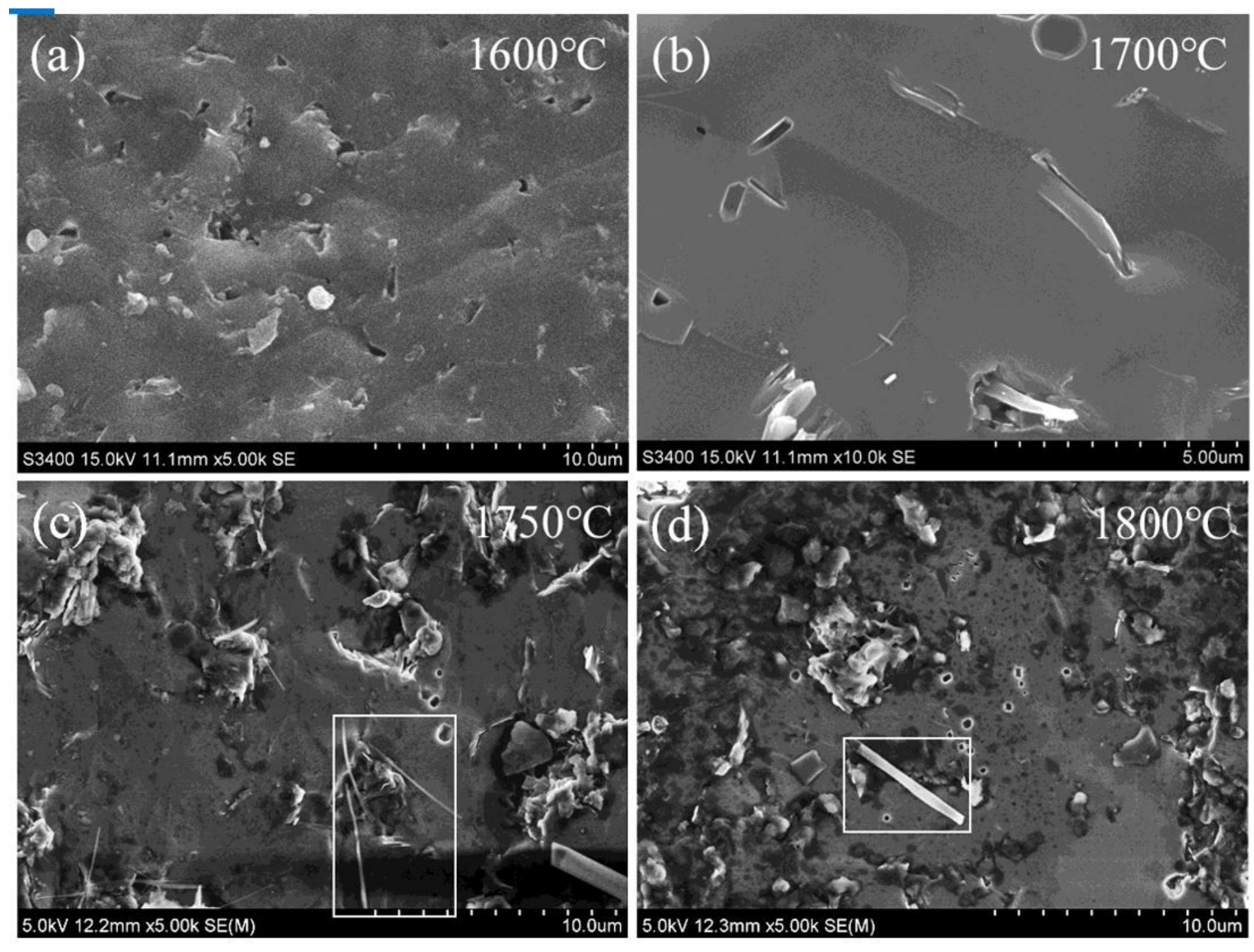

Figure 5

SEM images of the fracture surfaces of $\mathrm{H}-\mathrm{B} 4 \mathrm{C}$ ceramics fabricated by sintering at different temperatures with adding $5 w t . \%$ BNNTs.
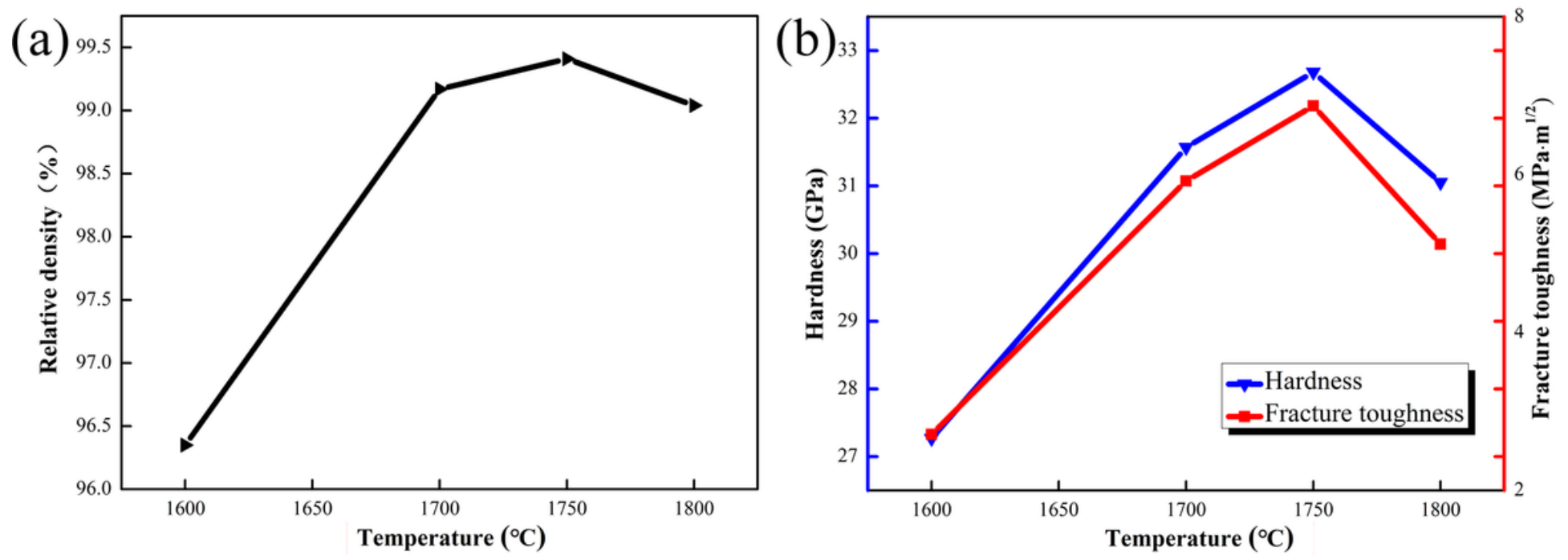


\section{Figure 6}

The relative densities and mechanical properties of B4C samples fabricated at different sintering temperatures with adding 5wt.\% BNNTs.


\section{Figure 7}

SEM images of the BNNTs/B4C composites: (a) and (c) fracture surface. The schematic indicated various toughening mechanisms: (b) BNNTs pull out. (d) BNNTs bridging. 